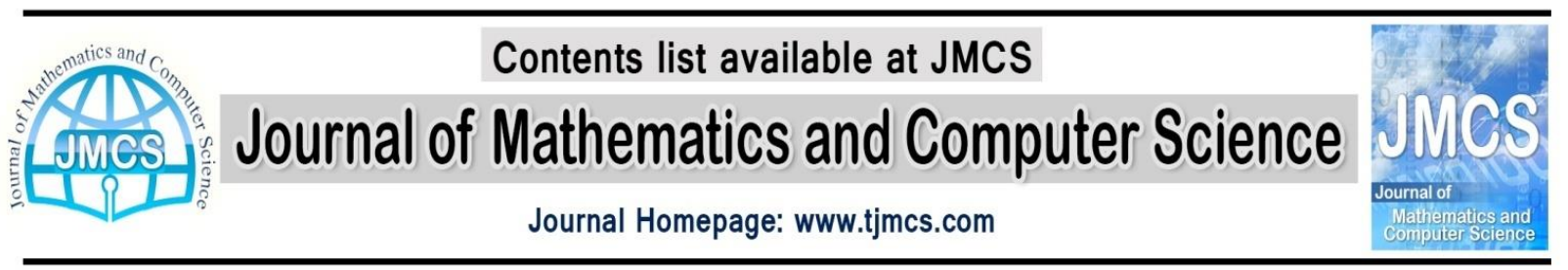

\title{
Choose the Best Project Based on Simulation Optimization and Ant Colony Optimization Algorithm
}

\author{
Hamid Reza Feili ${ }^{1}$, Alireza Farsi ${ }^{2}$, Niloofar Nobahari ${ }^{3}$ \\ ${ }^{1}$ Faculty of Engineering, Department of Industrial Engineering, Islamic Azad University of Karaj, Iran, \\ Hrfeili@gmail.com \\ ${ }^{2}$ MBA; PUMBA (Pune University MBA); Pune, India, Tehran, Iran, \\ Alireza.farsi@gmail.com \\ ${ }^{3}$ Student of MBE; Amirkabir University of Technology; Tehran, Iran, \\ n.nobahari@aut.ac.ir.com
}

Article history:

Received February 2013

Accepted March 2013

Available online April 2013

\begin{abstract}
The process of planning, scheduling and economizing of new project is getting more difficult. Considering lack of raw materials, strict standards and tough competition, taking the right decision is not a simple task any more. In the process of globalization, only companies will be successful which are able to commercialize their dream with controlling effecting factors. Financial, operational and time bonded factors which sometimes follow accidental trends. Considering the probability behavior of this factors, benefiting from simulation approach to formulate the effect of these factors are one of the main solutions. Therefore under follow article we use simulation methodology to evaluate R\&D projects, affected by accidental factors. Bearing in mind with more repeat we minimize the mistakes in project and get to the optimize answer. To evaluate the projects, a financial model is being presented, including sales quantity and price to calculate the profit. Total cost is being calculated based on unit cost. To find the best answer we repeat the model more than 800 times with the help of Ant colony optimization algorithms. To elaborate on model, we have studied an operational unit and will show the sensitivity and analysis of model. Later we will see the result with the help of diagrams.
\end{abstract}

Keywords: Simulation Optimization, Ant Colony Optimization Algorithms, Research and Development (R\&D)

\footnotetext{
${ }^{1}$ Corresponding author
} 


\section{Introduction}

For an organization choosing the best development among available project is not always a simple activity. Business owners are always interested in project which provides the highest ROI (return on investment). Long term investment is always suffer from uncertainty and changing in working environments, therefore in any industry defining the proper long-term investment is always a challenge.

over recent years new method have been in practice methods have been in practice like; NPV ${ }^{4}$, IRR ${ }^{5}, \mathrm{ROR}^{6}$ most of these methods enjoy reduce cash flow .Despite realistic situation; in this article we consider the project should be run during the timetable and after starting the project no change is possible.

Over the last decade plenty of researches on application of simulation, optimization or mix of both on management and new project development have been took place.In Monte-Carlo algorithm and simulation optimization article, Ahmad Javad proposed a model to choose the best decision for a production unit (2012). Guangqiu Huang, Weiwei Gao, with the help of genetic model proposed an model to expand a city.(2011), Robert Brunet, Gonzalo Guillén-Gosálbez, J. Ricardo Pérez-Correa, José Antonio Caballero ,also used simulation method to design an optimize model for biotechnological process. Mohamed A.Ahmed and Alkhamis (2006) studied the application of hooke jeeves algorithm on simulation optimization. Over 2007, they published the result of their study on service extension on a service company with the help of simulation optimization. Yi Yeh and Shan Lin (2007) also work on optimize service quality with minimization of service quantity with the help of Genetics algorithm and simulation techniques. At the end Fong-Vhing Young (2009) published an article on simulation optimization for published development strategy which used Genetics algorithm, Monte-Carlo algorithm and simulation optimization.

As you see. The application of simulation method can be used in different varieties and can be expanded to a wide range of industries. So with the help of appropriate mathematical method and proper model, one can choose the best respond of market development.

The aim of this article is to show the companies flexibilities.it use option value approach to find out the value of each decision over a period.it also includes the uncertainty factors. Initially we describe the product development financial methods, and we put them in practice for cell phone producer company.at the end we do sensitivity analysis to find out the best time to start the project.

\section{Financial Model for Project Development}

Total sales income is being calculated based on two factors; sales quantity and selling price. One the other hand sales quantity is directly related to production and demand, in a same manner demand is also depend on market size, share and growth. Total production cost is being calculated based on production quantity, production cost and variable cost.

If consider $\mathrm{g}(\mathrm{t})$ as market growth,M1(t) as market share and M2 as Market size for a product in a $\mathrm{s}$ specific time period, then the product demand is calculated based on below formula;

$$
\mathrm{D}(\mathrm{t})=\mathrm{g}(\mathrm{t}) \times \mathrm{M} 2 \times \mathrm{M} 1(\mathrm{t})
$$

On the other hand if consider production quantity as $\mathrm{Q}(\mathrm{t})$,number of production as "Z", Production rate as "PR" and Number of factories as "F", then the production quantity is calculated based on below formula;

$$
\mathrm{Q}(\mathrm{t})=\mathrm{Z} \times \mathrm{PR} \times \mathrm{F}
$$

If the demand is more than production quantity, sales quantity, $\mathrm{S}(\mathrm{t})$,follow one of the below equations;

\footnotetext{
${ }^{4}$ Net Present Value

5 Internal rate of return

${ }^{6}$ Rate of return
} 


$$
\begin{aligned}
& \mathrm{D}(\mathrm{t})>\mathrm{Q}(\mathrm{t}) \rightarrow \mathrm{S}(\mathrm{t})=\mathrm{Q}(\mathrm{t}) \\
& \mathrm{D}(\mathrm{t})<\mathrm{Q}(\mathrm{t}) \rightarrow \mathrm{S}(\mathrm{t})=\mathrm{Q}(\mathrm{t})
\end{aligned}
$$

Consider $\mathrm{P}(\mathrm{t})$ as a price for specific period of time "N" and consider price increase base on Geometric series parameters, net value of the product, A1,interest rate "I" which will be fix to simplify the calculation and specific yearly increase rate "g".

$$
P=A_{1}\left[\frac{1-(F \mid P, g, n)(P \mid F, g, n)}{i-g}\right]=A_{1}\left[\frac{1-(1+g)^{N}(1+i)^{-N}}{i-g}\right]
$$

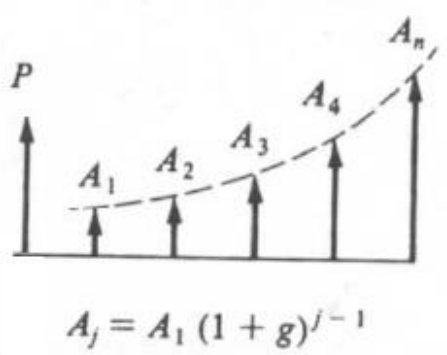

Figure 1. Geometric series

Then Sales income $\mathrm{R}(\mathrm{t})$ is calculated based on follow formula;

$$
\mathrm{R}(\mathrm{t})=\mathrm{S}(\mathrm{t}) \times \mathrm{P}(\mathrm{t})-\mathrm{Q}(\mathrm{t}) \times \mathrm{V}-\mathrm{K}
$$

Which "V" stands for variable cost and "K" shows total development cost.

If $\mathrm{C}(\mathrm{t})$ is equal to total cost of production for period " $\mathrm{N}$ " of fix cost " $\mathrm{C}$ ", yearly operation cost of " $\mathrm{y}$ " and scrap value as " $\mathrm{M}$ ", to find out the total cost of production we should deduct scrap value from fix production cost and yearly operation cost, here we use Uniform-Series Present Worth Factor formula and Single-Payments Present Worth Factor formula to calculate scrap value.

$$
C(t)=C+y(P \mid A, i, n)-M(P \mid F, i, n)
$$

Here, net profit calculated based on;

$$
\mathrm{F}(\mathrm{t})=\max \{0, \mathrm{~S}(\mathrm{t}) \times \mathrm{P}(\mathrm{t})-\mathrm{Q}(\mathrm{t}) \times \mathrm{V}-\mathrm{K}\}
$$




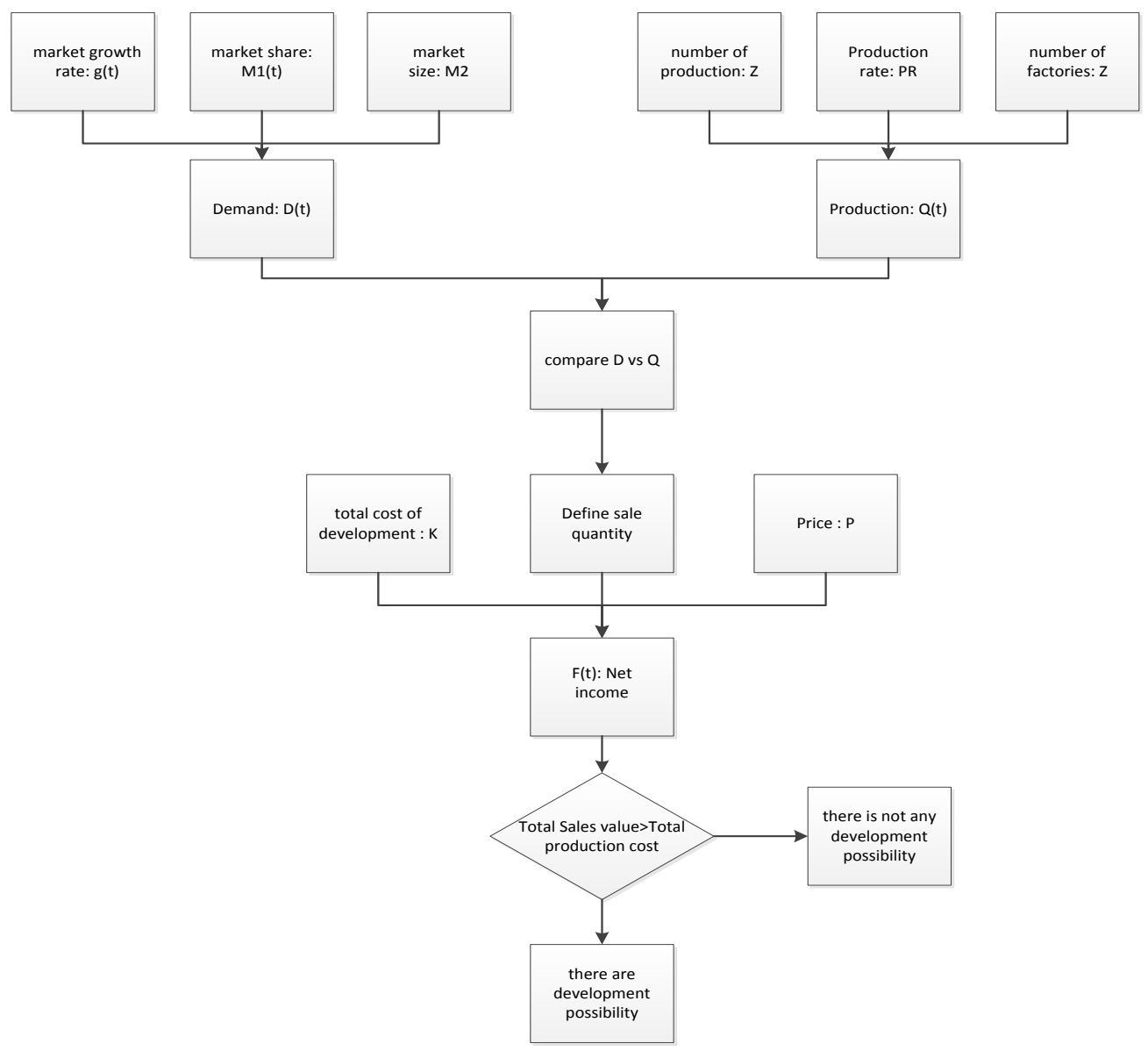

Figure 2. Shows the relation among each parameters and formula

In the mention calculation, we use present value to calculate the possibility of development project, this method mostly known as $\mathrm{NPW}^{7}$. under this method all income and cost are calculated based on the starting point of the project.to define the profitability of a project we can use MARR ${ }^{8}$ under below formula;

$$
\mathrm{NPW}=\mathrm{PWB}^{9}-\mathrm{PWC}^{\prime}
$$

Considering above formula, we can expect three scenarios;

- $\mathrm{NPW}<0$ : the project is not reasonable; present value of cost is more than present values of income.

- NPW>0: the project is reasonable; present value of cost is less than present values of income.

- $\mathrm{NPW}=0$ : the project is reasonable; as project meet Minimum Acceptable Rate of Return.

These kinds of projects are known as Mutually Exclusive Projects which means acceptance of one

Project eliminates the others from consideration.

It should be consider, the appropriate respond has direct relation with the number of running the simulation. To find the optimize answer we have chosen the ant colony optimization algorithm.

\footnotetext{
${ }^{7}$ Net Present Worth

${ }^{8}$ Minimum Acceptable Rate of Return

9 Present Worth of Benefit

10 Present Worth of Cost
} 


\section{Ant Colony Optimization Algorithms}

Ants' behavior was sprit to expand this algorithm. Ants are social creature, they live in big colony and their behavior is fully related to existence of their colonies.

How ants try to find the shortest way to find the food was the main soul of this algorithm.

\subsection{Edge Selection}

An ant constructs a solution for the problem which it faces simply. At each iteration of the algorithm, an ant shift from a position $x$ to position $y$, corresponding to a more complete intermediate solution. Therefore, ant $k$ computes a set $A_{k}(x)$ of feasible expansions to its current position in each iteration, and shift to one of these in probability. For ant $k$, the possibility $p_{x y}^{k}$ of shifting from position $x$ to position $y$ depends on the combination of two values, the attractiveness $\eta_{x y}$ of the shift, as computed by some heuristic indicating the a priori desirability of that shift and the trail level $\tau_{x y}$ of the shift, shows how successful it was to make that particular shift.

The trail level shows a posteriori indication of the desirability of this shift. Trails are updated usually when all ants have completed their solution.

In general, the $k$ th ant shift from position $x$ to position $y_{\text {with probability }}$

$$
p_{x y}^{k}=\frac{\left(\tau_{x y}^{\alpha}\right)\left(\eta_{x y}^{\beta}\right)}{\sum\left(\tau_{x y}^{\alpha}\right)\left(\eta_{x y}^{\beta}\right)}
$$

Where $\tau_{x y}$ is the amount of pheromone deposited for transition from position $x$ to $y, 0 \leq \alpha$ is a parameter to control the influence of $\tau_{x y}, \eta_{x y}$ is the desirability of position transition $x y$ and $\beta_{\geq 1}$ is a parameter to control the influence of $\eta_{x y}$.

Pheromone update

By completing all solution, the trails are updated by

$$
\tau_{x y} \leftarrow(1-\rho) \tau_{x y}+\sum_{k} \Delta \tau_{x y}^{k}
$$

Where $\tau_{x y}$ is the amount of pheromone deposited for a position transition $x y, \rho_{\text {is }}$ the pheromone

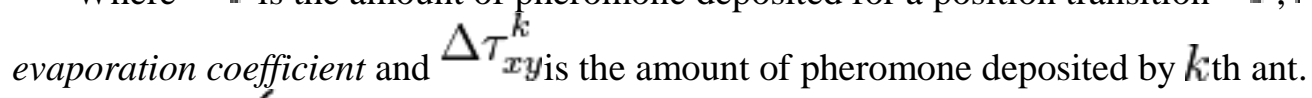

$$
\Delta \tau_{x y}^{k}= \begin{cases}Q / L_{k} & \text { if ant } k \text { uses curve } x y \text { in its tour } \\ 0 & \text { otherwise }\end{cases}
$$

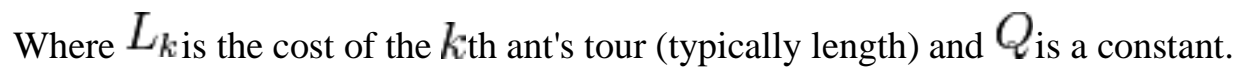




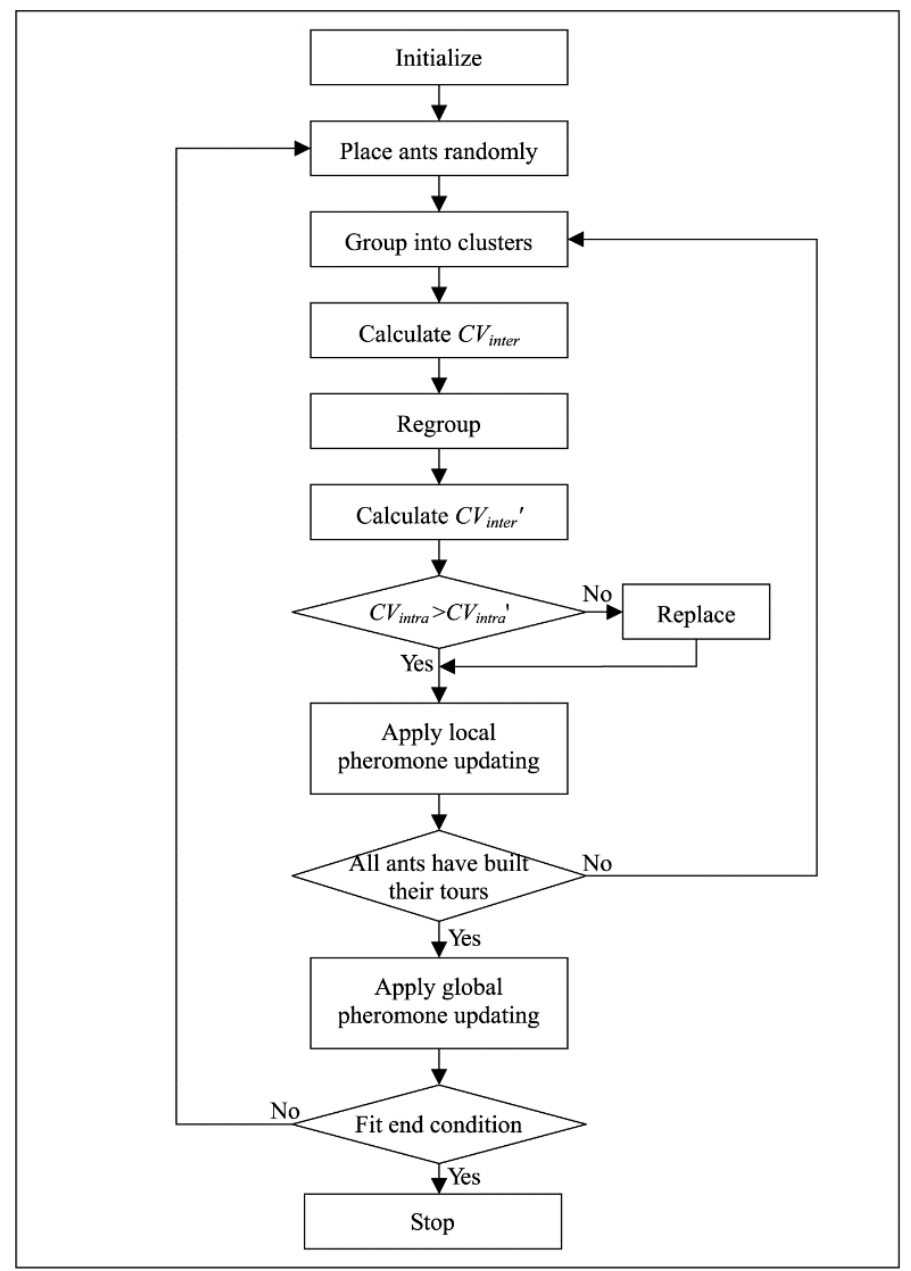

Figure 3. Shows describes the model simply

\section{Analysis on Simulation Optimization to Strategy Development}

To have an example; we have chosen a cellphone producer which is working on three new project. This producer should invest in specified project to keep its presence in market over a special period of time. Let's consider given data;

- Market growth $\mathrm{g}(\mathrm{t}): 0.4-16 \%$

- Market Share, M1(t):11.9\%-13\%

- Present value of Product,A1;Type1:620’000,type2:490’000,type3:565’000 IRR(money unit)

- Market Size,M2:32055 pcs

- Interest rate, $\mathrm{i}: 25 \%$

- Constant rate,g:7\%

- Production quantity of each factory,Z;Type1:60000,Type2:80000,Type3:100000

- Production rate for each factory,PR,Type1:65\%,Type2:74\%,Type3:80\%

- Project life for each factory,Type1:24 months,Type2:48,Type3:12 months

- Time horizon: not specified

- Production fix cost, C, Type 1:21'600,type2:26’320,type3:29'870 IRR(money unit)

- Number of factories,F:3 
- Risk rate for each quarter,r:1.23\%

- Variable production Cost,V:100 IRR(money unit)

- Yearly operation cost,y,Type1:6’000,Type2:7’400,Type3:8'250 IRR(money unit)

- Scrap value for each factory,M,Type1:3'100,Type2:3'800,Type3:4'000 IRR(money unit)

- Development cost for each factory,K,Type1:1.4 million IRR, Type2:2.3 million IRR, Type3:2.5 million IRR,

The figures for using in the algorithms are as follow:

- $\alpha=0.4$

- $\beta=0.9$

- $\rho=0.4$

- $\tau_{\mathrm{xy}}=0.001$

It should be consider which project life cycles are different and the time horizon is not specified, therefore common multiple of project is product life cycle of all projects to be compared. Therefore common multiple is equal to 48 months or four years. On the other hand, available parameters are limited to special intervals which need to be optimized for best result.

Here we use Monte-Carlo method. Monte Carlo methods are classified as computational algorithms that are based on repeated random sampling to compute their results.it is used in computer simulations of physical and mathematical and some economical systems. This method is suitable for calculating by a computer and tends to be used when it is infeasible to compute an exact result with a deterministic algorithm. While Monte Carlo methods are a comprehensive method, but it should be mentioned that other methods like Ant colony optimization can be put in place.

Genetic algorithm is based on search heuristic that mimics the process of natural evolution. It leads to solutions to optimization problems using techniques inspired by natural evolution, like inheritance, mutation, selection and crossover.

Under genetic algorithm, a population of strings called chromosomes improves toward better solutions. This improvement usually starts from a individual random population generation. In each generation, the fitness of each individual in the population is assessed. Based on their fitness, multiple individuals are stochastically selected from the current population (and modified (recombined and possibly randomly mutated) to form a new population. The new population is then used in the next iteration of the algorithm.

This algorithm terminates in two manners;

- When either a maximum number of generations have been produced, (a satisfactory solution may or may not have been reached.)

- A satisfactory fitness level has been reached for the population

Refer to relations we described above and given data, the article will try to find out the best development project, best time for development and probability of profitability for each project.it should be bear in mind which the accuracy of result is directly related to frequency of simulation.

The simulation starts from first half of first year shows with $\mathrm{H} 11$ and in a same manner we will have $\mathrm{H} 12, \mathrm{H} 21, \ldots, \mathrm{H} 42$.Table1 includes 5 levels of simulation. 
Hamid Reza Feili, Alireza Farsi, Niloofar Nobahari / J. Math. Computer Sci. 7 (2013) 101 - 111

Table 1. Simulation result after 5 level of simulation

\begin{tabular}{|c|c|c|c|c|c|c|c|}
\hline H11 & H12 & H21 & H22 & H31 & H32 & H41 & H42 \\
\hline 189502510 & 450545564 & 74865554.93 & 502667486 & 255682721.2 & 925323148 & 78735064.4 & 140656926 \\
\hline 1416944075 & 38023720.2 & 1794712452 & 19653915 & 446600393.8 & 194973667 & 294220816 & 89565005.3 \\
\hline 3085150085 & 396252165 & 114196946.8 & 0 & 135238966 & 173799152 & 0 & 0 \\
\hline 0 & 1282041723 & 95629004.96 & 280242573 & 2008511430 & 97825567 & 73456886.1 & 228351137 \\
\hline 3367938240 & 354084897 & 119380138.2 & 409656110 & 408218433.9 & 0 & 1161176971 & 109662482 \\
\hline 9285706.21 & 517991049 & 138295867.1 & 474189624 & 28815317.34 & 711696155 & 397486222 & 64827120.8 \\
\hline 65969757.1 & 139537637 & 59894995.63 & 138251452 & 980828486.6 & 84842625 & 889000020 & 0 \\
\hline 958229279 & 0 & 0 & 458228136 & 374270512.5 & $1.182 \mathrm{E}+09$ & 0 & 126695656 \\
\hline 214439716 & 0 & 277033746.1 & 312574624 & 1199589848 & 0 & 29917881.9 & 0 \\
\hline 215901688 & 290508545 & 827162581.2 & 80162320.8 & 16858388.37 & 0 & 1604066698 & 208977543 \\
\hline 168905552 & 1162513469 & 381697991.1 & 449589522 & 300863734.6 & 0 & 58910609.1 & 168910064 \\
\hline 8889311.3 & 1555427808 & 631534.4695 & 702764779 & 95482171.81 & 0 & 1264240793 & 416082673 \\
\hline 144004263 & 396204481 & 533773541.2 & 105645520 & 0 & 100061019 & 127853992 & 977797090 \\
\hline 158483652 & 2284317315 & 220779982.1 & 401285771 & 156781775 & 0 & 416603141 & 1116787427 \\
\hline 705794148 & 361199822 & 64672117.43 & 778137023 & 562629430.2 & 374530966 & 29097121.5 & 0 \\
\hline
\end{tabular}

After running Ant colony algorithm for almost 800 times, follow result has been generated for $\mathrm{F}(\mathrm{t})$;

Table2. Average value after 800 simulations

\begin{tabular}{|l|l|}
\hline average of option 1 & 366783498.5 \\
\hline average of option 2 & 519276732.8 \\
\hline average of option 3 & 380008997.2 \\
\hline
\end{tabular}

The value of each project over a period of four years will be as follow;

Table3. The Value of each project over a period of 4 years

\begin{tabular}{|c|c|c|c|c|c|c|c|c|}
\hline & $\mathrm{H} 11$ & $\mathrm{H} 12$ & $\mathrm{H} 21$ & $\mathrm{H} 22$ & $\mathrm{H} 31$ & $\mathrm{H} 32$ & $\mathrm{H} 41$ & H42 \\
\hline Option1 & 131903249 & 509283746 & 329831019 & 230183942 & 688293004 & 259302172 & 549932042 & 321093552 \\
\hline Option2 & 1193289430 & 759283043 & 519364833 & 358270061 & 347289435 & 268394011 & 395367280 & 332810376 \\
\hline Option3 & 819238331 & 568291837 & 119340245 & 460012673 & 403942654 & 262039901 & 338993784 & 97181936 \\
\hline
\end{tabular}

For applying current algorithm we use present value of each project, which can be easily calculated by considering the annual interest rate and inflation rate.

While calculating frequency of each project after simulation for project with more than zero income, one can calculate the probability of each project. For current case the result are as follow:

Probability of not being profitable of each project:

- Project 1:0.1

- Project2:0.15

- Project3:0.2

- All project:0.0083 


\section{Sensitivity Analysis}

To get a better idea of dynamism of project, we can change the effective parameters such as market growth rate, market share and risk rate.

Let's get to each parameter;

\section{- Market growth rate}

With increase in growth rate, however in the beginning graph shows some decline, but finally the effect shows a liner increase trend in graph.

The result of effectiveness is ignorable before 0.8 , while follow that till 1 , we expect grand change.

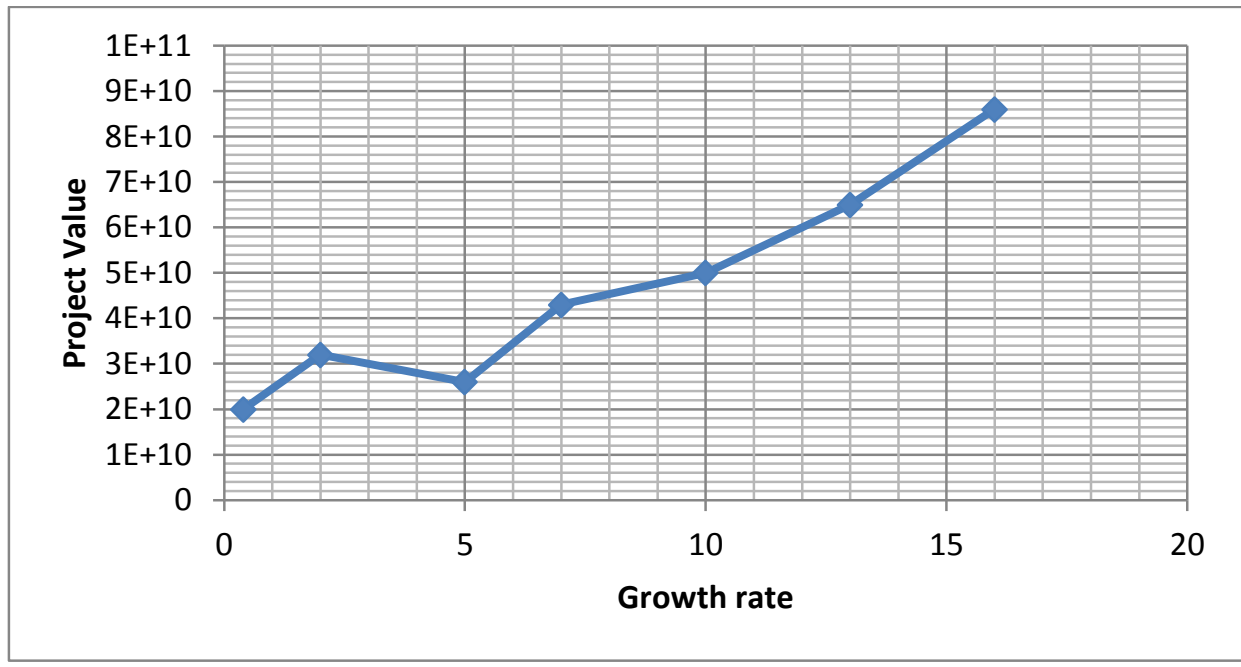

Figure 4. Effect of growth rate from .04 to $16 \%$ on project value

\section{- Risk rate}

Growth in the Risk rate will result in a decline on graph.

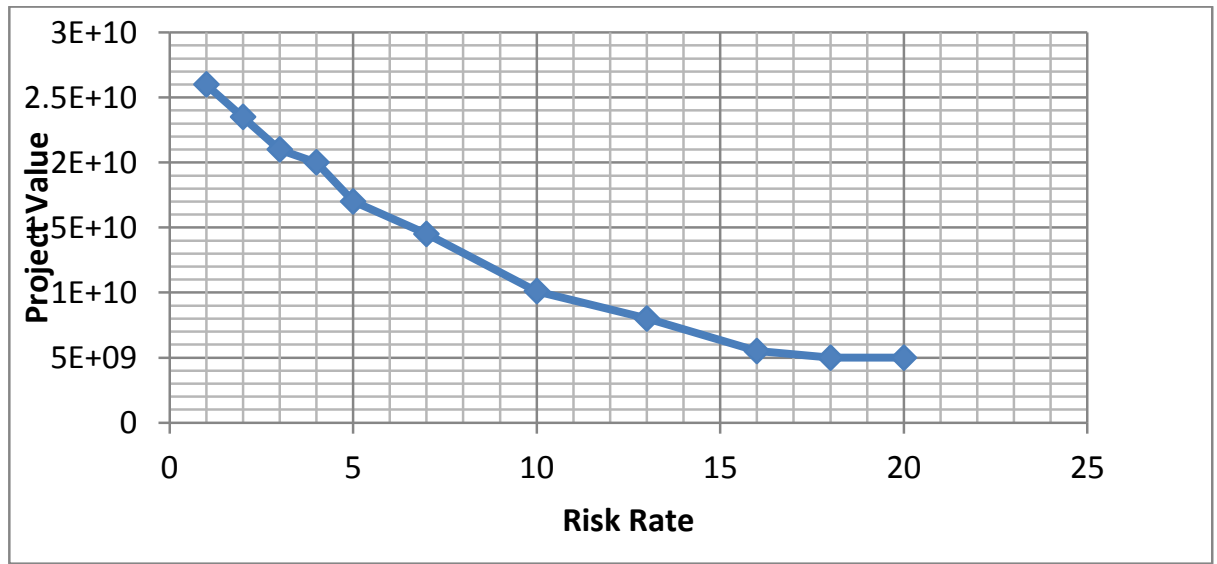

Figure 5. Effect of Risk rate on each project value 


\section{- Development Cost}

Any increase on development cost effect project value directly.

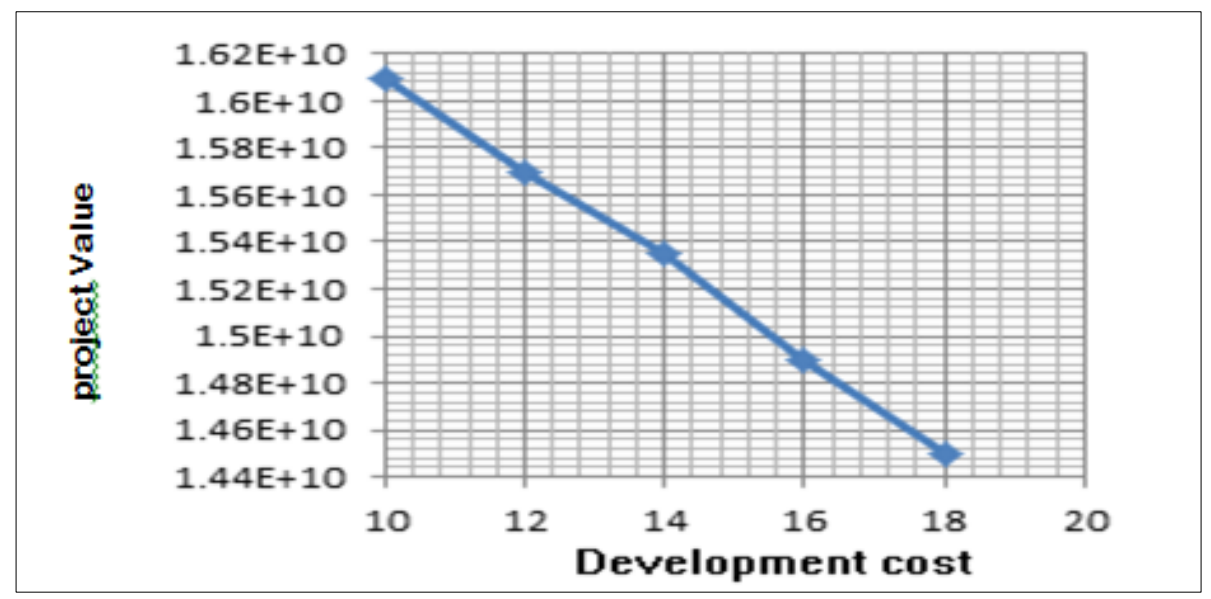

Figure 6. Effect of development cost on each project value

\section{Conclusion}

The article was looking to find out the best project over coming year through simulation method. This value can be analyze according to present value and base on profit rate. Therefore the best project can be chosen easily. Current approach shows the importance of management flexibility so they can change their decision to get to the best result. Simulation is one of the best tools which provide the best result compare to traditional methods. It provides the chance to include the realistic factors of problem. It should be kept in mind which the first step is decide to apply different project to improve the organization situation, then chose the best one with the help of simulation techniques.

Despite Monte-Carlo and Ant colony algorithms, there are plenty of new methods that can be used by other researchers to get more appropriate result.

\section{Reference}

[1] H. Feili, A. Farsi, N. Nobahari, Simulation optimization approach to strategy development (2012).

[2] A.J. Qureshi, Jean-Yves Dantan, V. Sabri, Paul Beaucaire, Nicolas Gayton, A statistical tolerance analysis approach for over-constrained mechanism based on optimization and Monte Carlo simulation, February 2012.

[3] G. Huang, W. Gao, Simulation Study on CA Model Based on Parameter Optimization of Genetic Algorithm and Urban Development, (2011).

[4] R. Brunet, G. Guillén-Gosálbez, J. Ricardo Pérez-Correa, J. Antonio Caballero, L. Jiménez, Hybrid simulation-optimization based approach for the optimal design of single-product biotechnological processes, February 2012.

[5] Mohamed A. Ahmed, Talal M. Alkhamis, Simulation optimization for an emergency department healthcare unit in Kuwait, (2009).

[6] Talal M. Alkhamis, Mohamed A. Ahmed, A modified Hooke and Jeeves algorithm with likelihood ratio performance extrapolation for simulation optimization, (2006).

[7] Jinn-Yi Yeh, Wen-Shan Lin, Using simulation technique and genetic algorithm to improve the quality care of a hospital emergency department, (2007). 
[8] Fong-Ching Yuan, Simulation-optimization mechacism for expansion strategy using real option theory, (2009).

[9] D. Subramanian, Joseph F. Pekny, and Gintaras V. Reklaitis, A Simulation-Optimization Framework for Research and Development Pipeline Management, 2001.

[10] S. Goss, S. Aron, J.-L. Deneubourg Pasteels, Self-organized shortcuts in the Argentine ant, Naturwissenschaften, volume 76, pages 579-581, (1989).

[11] J.-L. Deneubourg, S. Aron, S. Goss Pasteels, The self-organizing exploratory pattern of the Argentine ant, Journal of Insect Behavior, volume 3, page 159, (1990).

[12] D. Picard, A. Revel, M. Cord, An Application of Swarm Intelligence to Distributed Image Retrieval, Information Sciences, (2010).

[13] Xiao. M.Hu, J. ZHANG, and H. Chung, An Intelligent Testing System Embedded with an Ant Colony Optimization Based Test Composition Method, IEEE Transactions on Systems, Man, and Cybernetics--Part C: Applications and Reviews, Vol. 39, No. 6, pp. 659-669, Dec (2009).

[14] D. Merkle, M. Middendorf and H. Schmeck, Ant colony optimization for resourceconstrained project scheduling, Proceedings of the Genetic and Evolutionary Computation Conference (GECCO 2000), pp.893-900, (2000). 